\title{
Effects of Select Anions from the Hofmeister Series on the Gas-Phase Conformations of Protein lons Measured with Traveling-Wave Ion Mobility Spectrometry/Mass Spectrometry
}

\author{
Samuel I. Merenbloom, ${ }^{1}$ Tawnya G. Flick, ${ }^{1}$ Michael P. Daly, ${ }^{2}$ Evan R. Williams ${ }^{1}$ \\ ${ }^{1}$ Department of Chemistry, University of California, Berkeley, CA 94720-1460, USA \\ ${ }^{2}$ Waters Corporation, Pleasanton, CA, USA
}

\begin{abstract}
The gas-phase conformations of ubiquitin, cytochrome $c$, lysozyme, and $\alpha$-lactalbumin ions, formed by electrospray ionization (ESI) from aqueous solutions containing $5 \mathrm{mM}$ ammonium perchlorate, ammonium iodide, ammonium sulfate, ammonium chloride, ammonium thiocyanate, or guanidinium chloride, are examined using traveling-wave ion mobility spectrometry (TWIMS) coupled to time-of-flight (TOF) mass spectrometry (MS). For ubiquitin, cytochrome $c$, and $\alpha$-lactalbumin, adduction of multiple acid molecules results in no significant conformational changes to the highest and lowest charge states formed from aqueous solutions, whereas the intermediate charge states become more compact. The transition to more compact conformers for the intermediate charge states occurs with fewer bound $\mathrm{H}_{2} \mathrm{SO}_{4}$ molecules than $\mathrm{HClO}_{4}$ or $\mathrm{HI}$ molecules, suggesting ion-ion or salt-bridge interactions are stabilizing more compact forms of the gaseous protein. However, the drift time distributions for protein ions of the same net charge with the highest levels of adduction of each acid are comparable, indicating that these protein ions all adopt similarly compact conformations or families of conformers. No significant change in conformation is observed upon the adduction of multiple acid molecules to charge states of lysozyme. These results show that the attachment of $\mathrm{HClO}_{4}, \mathrm{HI}$, or $\mathrm{H}_{2} \mathrm{SO}_{4}$ to multiply protonated proteins can induce compact conformations in the resulting gas-phase protein ions. In contrast, differing Hofmeister effects are observed for the corresponding anions in solution at higher concentrations.
\end{abstract}

Key words: Ion mobility, Mass spectrometry, Hofmeister series, Adduction, Conformation

\section{Introduction}

$\mathrm{T}$ he first reports of the effects of various salts on protein stability date back to 1888 , when F. Hofmeister investigated the effectiveness of different salts on precipitat-

Electronic supplementary material The online version of this article (doi:10.1007/s13361-011-0238-1) contains supplementary material, which is available to authorized users.

Correspondence to: Evan R.Williams; e-mail: williams@cchem.berkeley.edu ing egg white proteins [1]. Since that time, an ordering of ions based on their effects on the stabilities of biomolecules in aqueous solutions has been well established, and the topic of many reviews [2-10]. The effects are more pronounced for anions than cations, with the following general order:

$$
\begin{aligned}
\mathrm{F}^{-} & \approx \mathrm{SO}_{4}^{2-}>\mathrm{HPO}_{4}^{2-}>\mathrm{CH}_{3} \mathrm{COO}^{-}>\mathrm{Cl}^{-}>\mathrm{NO}_{3}^{-} \\
& >\mathrm{Br}^{-}>\mathrm{ClO}_{3}^{-}>\mathrm{I}^{-}>\mathrm{ClO}_{4}^{-}>\mathrm{SCN}^{-}
\end{aligned}
$$


Anions to the left of the series are referred to as kosmotropes, and greatly decrease protein solubility in aqueous solutions by stabilizing native conformations. At the other extreme are chaotropes, which increase protein solubility by destabilizing native conformations. This trend has been reproduced numerous times, with a few notable exceptions, including a reverse ordering of ions in some instances when the isoelectric point $(\mathrm{pI})$ of the protein is several units greater than the $\mathrm{pH}$ of the solution [11-15]. Highly-compact, yet non-native solution conformers have been observed for numerous proteins at low $\mathrm{pH}$ [16-18], and in some instances, the addition of chaotropes has stabilized these "molten globules" [18].

Despite numerous studies, the molecular origins of these Hofmeister phenomena are still hotly debated. Both ion-water and ion-protein interactions are purported to play roles, but it is not well established the extent to which each of these effects contribute. A variety of techniques, including nuclear magnetic resonance [16, 17, 19-22], X-ray crystallography [11, 13, 14], X-ray absorption spectroscopy [23, 24], femtosecond (fs) midinfrared pump-probe spectroscopy [25], sum-frequency generation spectroscopy (SFG) [6, 10, 26], Sephadex G-10 gel sieving chromatography $[27,28]$, Jones-Dole viscosity calculations [29], neutron [30, 31] and X-ray [32] diffraction, and molecular simulations [6, 9, 10, 19, 33-35] have been used to examine the Hofmeister effects, and conflicting evidence about the importance of ion-water versus ion-protein interactions have been reported. The extent to which ions can affect the structure of water at long distances has been a topic of debate $[6,25,26,33,35-37]$. Recently, both fs pump-probe spectroscopy of aqueous salt solutions [25] and SFG of aqueous solutions containing both salts and polymers [26] indicate that individual ions do not order water significantly beyond the first solvation shell. In striking contrast, recent infrared photodissociation (IRPD) experiments on ions in aqueous nanodrops have shown that sulfate dianion orders water molecules well beyond the first and second solvation shells [36], and that long-range patterning of water occurs for many different ions to various extents [37].

Few mass spectrometry (MS)-based experiments have intentionally examined nonspecific ion-protein interactions. Indeed, small cations (specifically $\mathrm{Na}^{+}$and $\mathrm{K}^{+}$) [38, 39] and anions $\left(\mathrm{SO}_{4}{ }^{2-}\right.$ and $\left.\mathrm{PO}_{4}{ }^{3-}\right)$ [40] are typically considered nuisances during the analysis of biological molecules by both ESI and matrix-assisted laser desorption ionization (MALDI)MS, and many steps have been taken to reduce their presence in the mass spectra of proteins [39-41] and nucleic acids [38, 42, 43]. The few MS studies involving the interactions of proteins with small ions have examined more the ion's effects on overall signal [44, 45], the observed charge state distribution [46, 47], how many ions (or neutral acid molecules of the anion) adduct to the protein [48-50], or how to best minimize ion adduction [39-41]. With respect to adduction of anions to protein ions, the anions sulfate [40], perchlorate [49, 50], and iodide [48] adduct to proteins, with the extent of adduction of the latter two anions correlating well [49] or exactly $[48,50]$ with the number of unmodified basic sites (arginine, lysine, histidine, and Nterminus) in the protein.

For ESI of macromolecular complexes, buffers or essential salts can be necessary to preserve the noncovalent interactions that hold the subunits together [51-53]. The retention of buffer or salt molecules on the ionized complex during droplet desolvation can complicate the determination of the complex's molecular weight. This is typically counteracted by increasing the harshness of conditions during ion desolvation, which might result in the alteration of the complex's conformation, further complicating any potential comparisons of the gasphase conformation to that adopted by the complex in solution [54]. Addition of low volatility salts to solutions of macromolecular complexes can help preserve these complexes in compact conformations as they enter the gas phase, even after significant ion activation in the source region [55]. However, any low-volatility molecules still bound to the complex will adversely affect accurate measurement of the molecular weight of the complex. A recent study of macromolecular complexes with a variety of anions show that some anions can adduct to complexes and preserve compact conformations, yet can be readily removed by activating the ions without altering the complex ions' conformation [56].

Recent experiments with the proteins ubiquitin, cytochrome $c$, lysozyme, and insulin chain B electrosprayed from aqueous solutions containing millimolar concentrations of 11 different sodium-anion salts indicate that the levels of both acid molecule and sodium binding to each protein correlate well with the proton affinity of the anion and not with any solution properties of the anions, i.e., adduction did not follow a Hofmeister series [57]. Here, traveling wave ion mobility spectrometry (TWIMS) [58] coupled to MS is used to examine the effects of anion adduction (as multiples of the neutral acid $\mathrm{HX}$ ) on the gas-phase conformations of ubiquitin, cytochrome $c$, lysozyme and $\alpha$-lactalbumin, electrosprayed from aqueous solutions at neutral $\mathrm{pH}$. The anions perchlorate, iodide, and sulfate all cause charge states of ubiquitin, cytochrome $c$ and $\alpha$-lactalbumin with partiallyfolded conformers to adopt more compact conformations. The same amount of compact conformation(s) observed for a protein ion with a specific number of bound $\mathrm{H}_{2} \mathrm{SO}_{4}$ molecules is only seen for the same protein ion with at least twice as many bound $\mathrm{HClO}_{4}$ or $\mathrm{HI}$ molecules, suggesting salt-bridge interactions between the anion and protonated sites on the protein serve to compact the protein ion in the gas phase. For the highest and lowest charge states that are common to all solutions, acid binding does not result in a significant change to the observed drift time distributions. No significant change in conformation with increased adduction of molecules occurs for lysozyme, for which a reversed Hofmeister series is anticipated at $\mathrm{pH} \sim 7$.

\section{Experimental}

Ubiquitin ( $\geq 98 \%$ ), cytochrome $c(\geq 95 \%)$, lysozyme, the ammonium salts of chloride $(\geq 99.0 \%)$, perchlorate $(\geq 98.0 \%)$, 
iodide $(\geq 99.0 \%)$, thiocyanate $(\geq 99.0 \%)$, and sulfate $(\geq 99.0 \%)$, and guanidinium chloride $(\geq 99.0 \%)$ were purchased from Sigma-Aldrich (St. Louis, MO, USA) and were used without further purification. $\alpha$-lactalbumin $(\geq 85 \%)$ was also purchased from Sigma, and was desalted with $18 \mathrm{M} \Omega$ water using Bio-Rad Micro Bio Spin 6 columns (Bio-Rad Labs, Hercules, CA, USA). Solutions with a final concentration of $10 \mu \mathrm{M}$ protein and $5 \mathrm{mM}$ ammonium salt were prepared in $18 \mathrm{M} \Omega$ water (Millipore, Billerica, MA, USA) for analysis. Solutions containing only $10 \mu \mathrm{M}$ of each individual protein were also prepared in $18 \mathrm{M} \Omega$ water. All aqueous solutions, with and without added salts, had $\mathrm{pH}$ values $~ 7$. Experiments were performed using a Synapt G2 High Definition MS (Waters, Milford, MA, USA) equipped with a Z-spray ion source. Ions were formed with nanoelectrospray tips prepared by pulling borosilicate capillaries $(1.00 \mathrm{~mm}$ o.d./0.78 mm i.d.; Sutter Instruments, Novato, CA, USA) to a tip of $\sim 1 \mu \mathrm{m}$ i.d. on a Sutter Instruments P-87 Flaming/Brown micropipette puller. A $0.127 \mathrm{~mm}$ diameter platinum wire (Sigma, St. Louis, MO, USA) was inserted into the capillary in order to make electrical contact with the solution. Electrospray was initiated and maintained by applying a potential of $1.0-1.5 \mathrm{kV}$, relative to instrument ground, to the wire. The sampling and extraction cones were operated at potentials of 40 and $3 \mathrm{~V}$, respectively, and the trap was operated at a flow rate of $3.00 \mathrm{~mL} / \mathrm{min}$, collision energy of $4 \mathrm{~V}$ and bias of $45 \mathrm{~V}$.

The TWIMS mobility cell was operated with a constant wave velocity of $700 \mathrm{~m} / \mathrm{s}$, wave height of $40 \mathrm{~V}$, helium flow rate of $180 \mathrm{~mL} / \mathrm{min}$, and IMS $\left(\mathrm{N}_{2}\right)$ flow rate of $90 \mathrm{~mL} / \mathrm{min}$. Pressures were approximately $2.3,1.1 \times 10^{-3}, 2.5 \times 10^{-2}$, and $1.1 \times 10^{-6} \mathrm{mBar}$ in the backing, source, trap, and TOF regions, respectively. The TOF analyzer was operated in resolution ("V") mode, and all spectra were acquired for three minutes. Mass spectra were not smoothed, whereas drift time distributions were smoothed twice using the Waters Mass Lynx software built-in Savitzky Golay smooth with a 1 unit window.

\section{Results}

\section{Unadducted Protein Conformations from Aqueous Solution}

The conformations of gaseous protein ions formed by ESI are sensitive to many instrumental conditions, including ion injection energy [59-61], ion storage time prior to analysis [62-66], solvent temperature [67], and solvent composition [67]. Drift time distributions for charge states of ubiquitin $(\mathrm{pI}=6.79)$, cytochrome $c(\mathrm{pI}=9.59)$, lysozyme $(\mathrm{pI}=9.32)$, or $\alpha$-lactalbumin $(\mathrm{pI}=4.80)$ formed from pure water, and solutions containing millimolar concentrations of the ammonium salts of sulfate, perchlorate, or iodide were measured using otherwise identical experimental conditions. Each of the salt solutions had a $\mathrm{pH}$ of $\sim 7$, although acidification can occur during droplet evaporation [68].
TWIMS drift times can be converted to collision cross sections [54, 69, 70]. However, the most accurate calibrations for small proteins, such as the ones studied here, are for the denatured forms [70]. Even with careful control of instrumental parameters, errors up to $5 \%$ have been recently reported [70]. This uncertainty can be attributed to a number of factors, including changes in the distributions of conformers observed for a charge state with changes in the traveling wave height and velocity [71]. Recently, experiments with the $p$-methoxybenzylpyridinium ion show that ion heating can occur with increasing traveling wave height, increasing wave velocity, or decreasing pressure in the drift cell [72]. Ion heating induced by the TWAVE measurement may also cause changes in protein conformation to occur, although this effect appears to be minimal for large multiprotein complexes [73]. For these reasons, drift distributions are not plotted on a collision cross section scale. Both staticfield IMS [59, 60] and TWIMS [69] data are often plotted on a normalized drift time scale, in which drift times are multiplied by the ion charge for the purposes of comparing features across different charge states. We normalized the drift times by multiplying by charge, charge squared [74], and the protocol of Ruotolo et al. [54], and a comparison is provided in the Supplemental Material. Results from multiplying drift time distributions by charge for charge states of ubiquitin (a), cytochrome $c$ (b), and lysozyme (c) are shown in Figure 1.

ESI of ubiquitin from aqueous solutions results in formation of the 4+ through $9+$ charge states, and the charge-normalized TWIMS arrival time distributions for these ions are shown in Figure 1a. The ubiquitin conformers have normalized drift times ranging from $35(4+$ and $5+$ ions) to $75(8+$ and $9+$ ions $) \mathrm{ms}$. For the lowest charge states (4+ and 5+), broad, unresolved peaks centered about 47.72 and $49.75 \mathrm{~ms}$ are the most pronounced features. The distributions for $6+$ and $7+$ ions are also broad, with maxima at normalized drift times of 70.26 and $71.19 \mathrm{~ms}$, respectively. For the $8+$ and $9+$ ions, sharp peaks centered about normalized drift times of $69.04 \mathrm{~ms}$ and $70.74 \mathrm{~ms}$, are the only features. An increase in normalized drift times with increasing charge state has been observed for proteins using static-field IMS [59, 75, 76], where low charge state ions have collision cross section (ccs) values closest to those calculated using solution-phase structures, whereas the ions with the highest charge states have ccs values suggesting they are nearly completely devoid of secondary structure $[59,75]$. The arrival time distributions for the $4+$ through $9+$ charge states formed by ESI out of $49 \%$ water, $49 \%$ acetonitrile, 2\% acetic acid (dotted lines) are similar to those out of pure water. The $10+$ through $13+$ charge states were also formed out of the denaturing solution, and had greater normalized drift times than the 9+ charge state out of both solutions (Supplemental Material Figure S1).

The distributions for ubiquitin ions formed by ESI out of either aqueous or denaturing solutions do not resemble the drift profiles observed for the same charge states using 

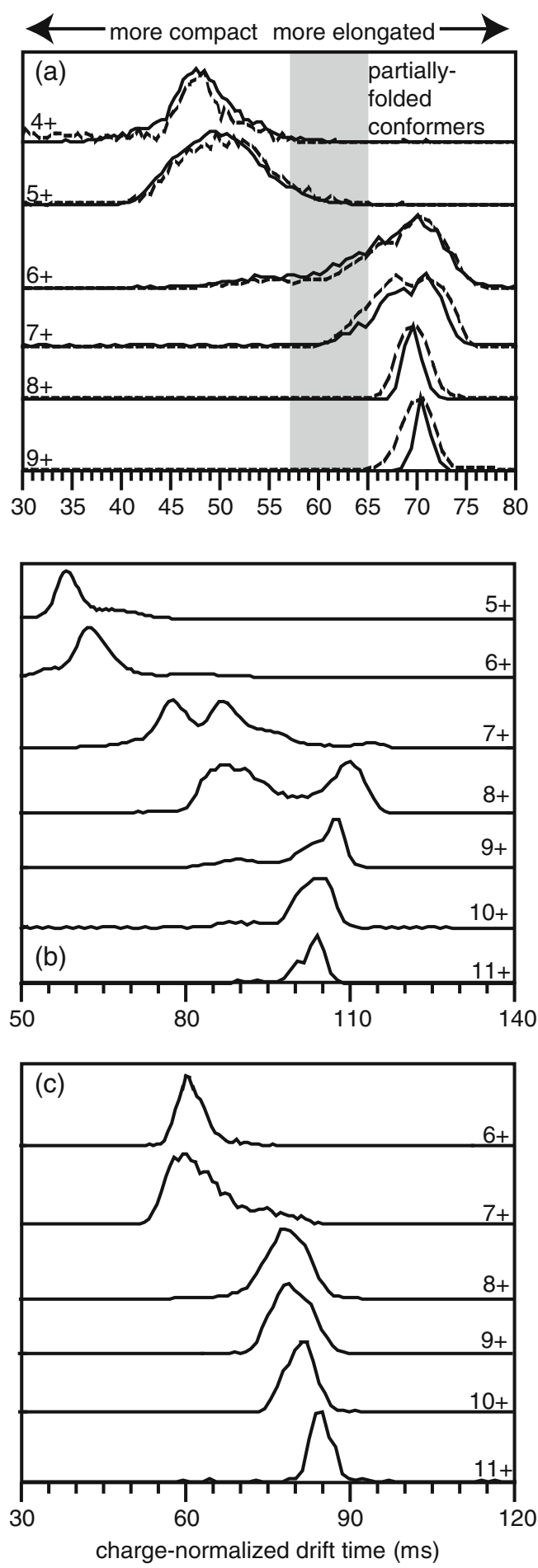

Figure 1. Charge-normalized TWIMS drift time distributions of the $4+$ through $9+$ charge states of ubiquitin (a) formed from pure water (solid lines) and 49\% water, 49\% acetonitrile, $2 \%$ acetic acid (dotted lines), 5+ through 9+ charge states charge states of cytochrome $c$ formed from pure water (b), and 6+ through 11+ charge states of lysozyme formed from pure water (c). Distributions are obtained by integrating intensities across $\mathrm{m} / \mathrm{z}$ values corresponding to the protonated form of each charge state from the two-dimensional dataset. For ubiquitin, drift times corresponding to partially-folded conformers are highlighted static-field IMS under gentle source conditions [76]. Staticfield IMS distributions for ubiquitin charge states show a transition from compact to partially-folded conformers as the charge state increases from $7+$ to $8+$, as well as multiple features for both the $8+$ and $9+$ charge states. The TWIMS data indicate that a transition from more compact to more elongated conformers occurs between the $5+$ and $6+$ charge states, which suggests that some ion heating occurs in these TWIMS experiments. Sharp peaks with low mobilities for both the $8+$ and $9+$ charge states indicate a limited number of unfolded conformers with similar extents of elongation, and elongation continues to increase with increasing charge. Based on comparison of the distributions in Figure 1a to the data of Koeniger and Clemmer [76], ions with normalized drift times greater than $65 \mathrm{~ms}$ correspond to elongated conformations, whereas the $4+$ and $5+$ ions have more compact conformations.

Similar elongation of conformers was observed for cytochrome $c$ (Figure 1b). These data indicate both partially-folded and elongated conformers for the $7+$ and $8+$ charge states, whereas the $7+$ was highly compact and the $8+$ exhibited both compact and partially-folded conformers at low injection energies and/or short storage times prior to injection in staticfield IMS [61, 62]. For lysozyme (Figure 1c), ions with 6+ and $7+$ charges have normalized drift times of $\sim 60 \mathrm{~ms}$, whereas ions with $8+$ or more charges have drift times of $\sim 80 \mathrm{~ms}$. This transition from more compact to more elongated conformers as the charge state increases from $7+$ to $8+$ is most consistent with the distributions observed by Valentine and Clemmer at intermediate injection voltages [60].

Experiments performed on the first generation Synapt have shown that both the amplitude and frequency of the traveling wave used in the mobility cell can potentially affect protein ion conformations [71, 74]. Greater elongation was reported to occur with lower wave heights and/or higher wave velocities. In our experiments, these parameters were set to values for which loss of adduct molecules from the protein ions was minimized. It is likely that ion heating in the trap region or mobility cell of the instrument causes unfolding of some intermediate charge states of these protein ions to occur. Therefore, because differences in the conformations adopted by individual charge states are examined, data are reported on a drift time scale. Greater drift times correspond to lower mobilities and greater collision cross sections.

\section{IMS Reduces Chemical Noise}

TWIMS-MS spectra were obtained under identical experimental conditions for ubiquitin electrosprayed out of solutions containing the ammonium salts of chloride, perchlorate, iodide, sulfate, thiocyanate, or guanidinium chloride. The two-dimensional drift time $(\mathrm{m} / \mathrm{z})$ plot of $10 \mu \mathrm{M}$ ubiquitin electrosprayed out of an aqueous solution of $5 \mathrm{mM}\left(\mathrm{NH}_{4}\right)_{2} \mathrm{SO}_{4}$ is shown in Figure 2. An integrated mass spectrum (Figure 2, left), obtained by summing intensities across all drift time values, shows the most 
abundant ions that are produced. A complicating factor for analyzing proteins in the presence of millimolar levels of various salts is potential mass interference from salt clusters. For example, there is considerable ion signal from cluster ions at lower $\mathrm{m} / \mathrm{z}$ values, and several high abundance $\left[\left(\mathrm{NH}_{4}\right)\right.$ $\left.\mathrm{HSO}_{4}\right]_{n} \mathrm{NH}_{4}^{+}$ions are labeled in the full mass spectrum. There are several charge state families of cluster ions in the two-dimensional spectrum, with $z=4$ clusters spanning a range of $\mathrm{m} / \mathrm{z}$ values of $\sim 1100-1900$. The extensive overlap of cluster ions with protein ions over a wide range of $\mathrm{m} / \mathrm{z}$ values is a significant source of chemical noise. For example, clusters obscure detection of many ubiquitin ions with $z=4+$ charges (circled) in the full mass spectrum. As the expanded view of the full mass spectrum shows, the $4+$ ion with nine $\mathrm{H}_{2} \mathrm{SO}_{4}$ molecules attached is the only $4+$ ion that can unambiguously be identified without TWIMS separation.

By dispersing ions in the TWIMS cell prior to mass analysis, it is possible to separate protein ions from overlapping sources of chemical noise, when their mobilities are different [77-81]. Examples of extracted ion mass spectra for highlighted regions corresponding to ubiquitin $4+, 6+$, and $8+$ ions are shown to the right of the twodimensional plot in Figure 2. The uppermost extracted mass spectrum shows ubiquitin $4+$ ions with zero through nine adductions of neutral $\mathrm{H}_{2} \mathrm{SO}_{4}$. Only one of these lowabundance ions can be identified in the full integrated mass spectrum. Ions corresponding to the adduction of one and two $\mathrm{H}_{2} \mathrm{SO}_{4}$ molecules to ubiquitin 4+ have a signal-to-noise ratio of 33 in the extracted mass spectrum, whereas these ions are not observed in the full mass spectrum, illustrating the advantage of the drift separation in improving detection limits by lowering chemical noise [77-81]. [M+4H+ $\left.9 \mathrm{H}_{2} \mathrm{SO}_{4}\right]^{4+}$ is the most abundant $4+$ ion. The sum of the number of acid molecules and protons for the most abundant ion is equal to the 13 basic sites in ubiquitin. This correlation between adduction and the number of basic residues has been reported previously [48-50].

\section{Conformations of Ubiquitin 6+ with Adducts of $\mathrm{H}_{2} \mathrm{SO}_{4}, \mathrm{HClO}_{4}$, and $\mathrm{HI}$}

Drift profiles can be extracted from the two-dimensional plot in order to examine conformational changes that may occur as a result of adduction of multiple acid molecules to protein ions. Data is plotted as a function of drift time for each individual charge state, taking into account the time ions spent in the transfer TWAVE and time-of-flight MS analyzer $[54,70]$. In some instances, multiple features were observed in the distribution. To simplify data presentation, peaks are labeled with Roman numerals, with increasing numerals corresponding to increasing drift times and therefore decreasing mobility and increasing collision cross section. Shoulders on a peak are designated with lowercase letters.

Drift profiles for ubiquitin $6+$ ions with between zero and five molecules of $\mathrm{H}_{2} \mathrm{SO}_{4}$ (a), $\mathrm{HClO}_{4}$ (b), and $\mathrm{HI}$ (c) adducted are shown in Figure 3. Drift distributions for (ubiquitin $+6 \mathrm{H})^{6+}$ with no adducts are broad and are similar from each of the three solutions (bottom three profiles). There is an abundant peak (labeled IIIb) with a higher mobility shoulder (IIIa). These three profiles are also remarkably similar to the distribution for (ubiquitin + $6 \mathrm{H})^{6+}$ ions formed from pure aqueous solution (Figure 1a) as are the profiles for (ubiquitin $+6 \mathrm{H})^{6+}$ from aqueous solutions containing $5 \mathrm{mM} \mathrm{NH} \mathrm{NH}_{4} \mathrm{Cl} \mathrm{NH}_{4} \mathrm{SCN}$, or guanidinium chloride (Figure 3). These data show that the conformation of the protein is not affected by $5 \mathrm{mM}$ concentration of these salts to an extent observable by TWIMS-MS, i.e., changes to the conformation of the protein induced by the salts in solution, if any, are not reflected in the distributions of conformers in the gas phase. Typically, significantly higher concentrations of salts are necessary to observe Hofmeister phenomena. These solutions all have $\mathrm{pH}$ values of $\sim 7$, but the ion concentration increases and the $\mathrm{pH}$ of the solution can change [68] during droplet evaporation, which makes it difficult to determine both the final $\mathrm{pH}$ and final concentration of each anion prior to protein ion formation.

In contrast, adduction of multiple $\mathrm{H}_{2} \mathrm{SO}_{4}, \mathrm{HClO}_{4}$, and $\mathrm{HI}$ molecules does affect the conformation of the gas-phase protein ion. The drift profile for (ubiquitin $\left.+6 \mathrm{H}+\mathrm{H}_{2} \mathrm{SO}_{4}\right)^{6+}$ has two new features, corresponding to a more-folded conformer (I), as well as an unresolved distribution of partially folded conformers (II). Adduction of two $\mathrm{H}_{2} \mathrm{SO}_{4}$ molecules to give (ubiquitin $\left.+6 \mathrm{H}+2 \mathrm{H}_{2} \mathrm{SO}_{4}\right)^{6+}$ results in feature I being the most intense peak, with very little of features II or III remaining. For ions with three or more $\mathrm{H}_{2} \mathrm{SO}_{4}$ molecules adducted, feature $\mathrm{I}$ is the only peak observed in the drift profile. These results indicate that adduction of two or more $\mathrm{H}_{2} \mathrm{SO}_{4}$ molecules causes these protein ions to adopt more folded conformations than observed for their bare counterparts under similar experimental conditions.

The drift profiles for ubiquitin $6+$ with multiple additions of $\mathrm{HClO}_{4}$ or $\mathrm{HI}$ are similar to each another. In contrast to results for $\mathrm{H}_{2} \mathrm{SO}_{4}$, attachment of one $\mathrm{HClO}_{4}$ or $\mathrm{HI}$ molecule to the protein ion results in little observable change in conformation compared with the bare 6+. Attachment of either two $\mathrm{HClO}_{4}$ or two $\mathrm{HI}$ molecules to the protein ion results in drift profiles rather similar to that observed for the attachment of one $\mathrm{H}_{2} \mathrm{SO}_{4}$ molecule. The relative intensity of feature $\mathrm{I}$ is slightly greater for the adduction of two $\mathrm{HI}$ molecules compared with the adduction of two $\mathrm{HClO}_{4}$ molecules, but this might be due, in part, to the more pronounced high mobility shoulder for $\mathrm{HClO}_{4}$ (Ia). This highly compact conformation is observed exclusively for ions with two or more $\mathrm{HClO}_{4}$ molecules adducted to the protein ion, is not observed for adduction of any number of $\mathrm{H}_{2} \mathrm{SO}_{4}$ or $\mathrm{HI}$ molecules, and might correspond to a nonnative, molten-globule-like conformation preserved by the adduction of $\mathrm{HClO}_{4}$ molecules. With three $\mathrm{HI}$ or $\mathrm{HClO}_{4}$ molecules adducted to the protein, peak I is the most intense 


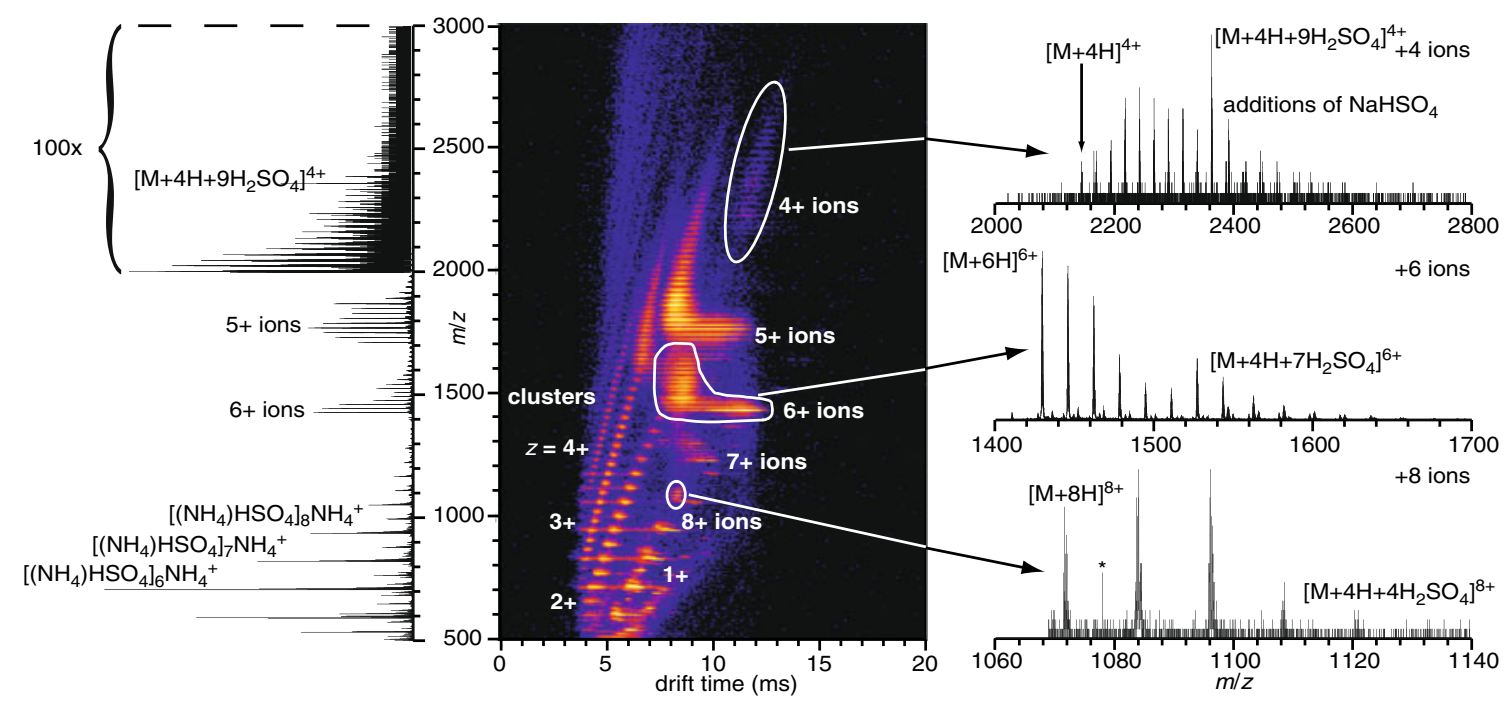

Figure 2. Two-dimensional drift time $(\mathrm{m} / \mathrm{z})$ plot obtained for ubiquitin ions formed from an aqueous solution of $5 \mathrm{mM}\left(\mathrm{NH}_{4}\right)_{2} \mathrm{SO}_{4}$ (center), along with the integrated mass spectrum, including a zoom-in on the region spanning $\mathrm{m} / \mathrm{z} 2000-3000$ (left). Extracted mass spectra for ubiquitin ions with $4+, 6+$, or $8+$ charges, obtained by integrating intensities across drift times in the regions of the two-dimensional plot highlighted by white circles are shown to the right. Noise peaks are highlighted with asterisks

feature in the drift profile and features II and III are much lower in intensity. Only feature I is observed upon adduction of five $\mathrm{HClO}_{4}$ or $\mathrm{HI}$ molecules to the protein ion.

For (ubiquitin $+5 \mathrm{H})^{5+}$, which was formed out of all three solutions, and for (ubiquitin $+7 \mathrm{H})^{7+}$, which was formed only from ammonium perchlorate and ammonium sulfate solutions (not shown), more compact conformations are observed when multiple acid molecules are adducted. As was observed for the $6+$, at least twice as many $\mathrm{HClO}_{4}$ or $\mathrm{HI}$ molecules adducted to the $5+$ and $7+$ were necessary to form a similar abundance of compact conformers compared with $\mathrm{H}_{2} \mathrm{SO}_{4}$ adducted ions. These results suggest that salt bridging or ionic interactions between the acid molecule and basic sites in the protein causes the protein ion to adopt more compact conformations in the gas phase. This compaction occurs more efficiently for dianions $\left(\mathrm{SO}_{4}{ }^{2-}\right)$ compared with monovalent anions $\left(\mathrm{ClO}_{4}^{-}, \mathrm{I}^{-}\right)$.

\section{Molecular Adduction to Ubiquitin 4+ and 8+ Ions}

To investigate how adduction of molecules affects protein ion conformations at both extremes of the conformational space (Figure 1), drift profiles for ubiquitin $4+$ and $8+$ ions with multiple adducts of $\mathrm{HClO}_{4}, \mathrm{HI}$, and $\mathrm{H}_{2} \mathrm{SO}_{4}$ molecules were examined (Figure 4). Ubiquitin 4+ was the lowest charge state formed from all three solutions, and these ions showed extensive adduction. The distribution of (ubiquitin + $4 \mathrm{H})^{4+}$ with no adducts formed from pure water (Figure 1) shows these ions are highly compact. Attachment of three $\mathrm{HClO}_{4}$, $\mathrm{HI}$, or $\mathrm{H}_{2} \mathrm{SO}_{4}$ molecules results in only very subtle shifts in the peak center to longer drift times, with the greatest shift for perchlorate ( $<4 \%$ increase). No significant change in conformation occurs through the adduction of nine molecules, the maximum to adduct to this charge state. By comparison, the change in drift times with molecular adduction for the $6+$ ions is significantly greater (up to $30 \%$ ). That no new features with shorter drift times are observed with increasing molecular adduction to the (ubiquitin $+4 \mathrm{H})^{4+}$ suggests that these ions may already have maximally compact conformations.

Data for multiple adducts to the $8+$ charge state, the highest charge state that was formed from salt solutions containing $5 \mathrm{mM}$ ammonium perchlorate or ammonium sulfate are shown in Figure 4 (right). The drift distribution for the bare $8+$ ion formed out of pure water (Figure 1a) shows this ion is more elongated compared to lower charge states. Addition of up to three $\mathrm{HClO}_{4}$ or three $\mathrm{H}_{2} \mathrm{SO}_{4}$ molecules results in $<3 \%$ increase in normalized drift times, indicating that there is no significant conformational change upon binding of multiple molecules. The absence of a conformational change for the $8+$ upon acid molecule adduction is consistent with a higher barrier to folding into a compact form than for the $6+$ and $7+$, despite having a similar extent of elongation.

\section{Cytochrome c 7+ with Multiple Adducts}

To assess if the results for ubiquitin are general, similar experiments were conducted with cytochrome $c$, lysozyme, and $\alpha$-lactalbumin. Cytochrome $c$ charge states ranging from $5+$ through $11+$ are formed by ESI from pure aqueous solutions. The charge-normalized drift profiles for these ions span a range of normalized drift times of 50-115 ms (Figure 1b). Only charge states between $6+$ and $8+$ were formed from all three solutions. Distributions for cytochrome $c 7+$ ions with multiple molecules of $\mathrm{H}_{2} \mathrm{SO}_{4}$ (a), $\mathrm{HClO}_{4}(\mathrm{~b}$ ), and $\mathrm{HI}$ (c) adducted are shown in Figure 5. As was the case for ubiquitin, the presence of the anion in the 

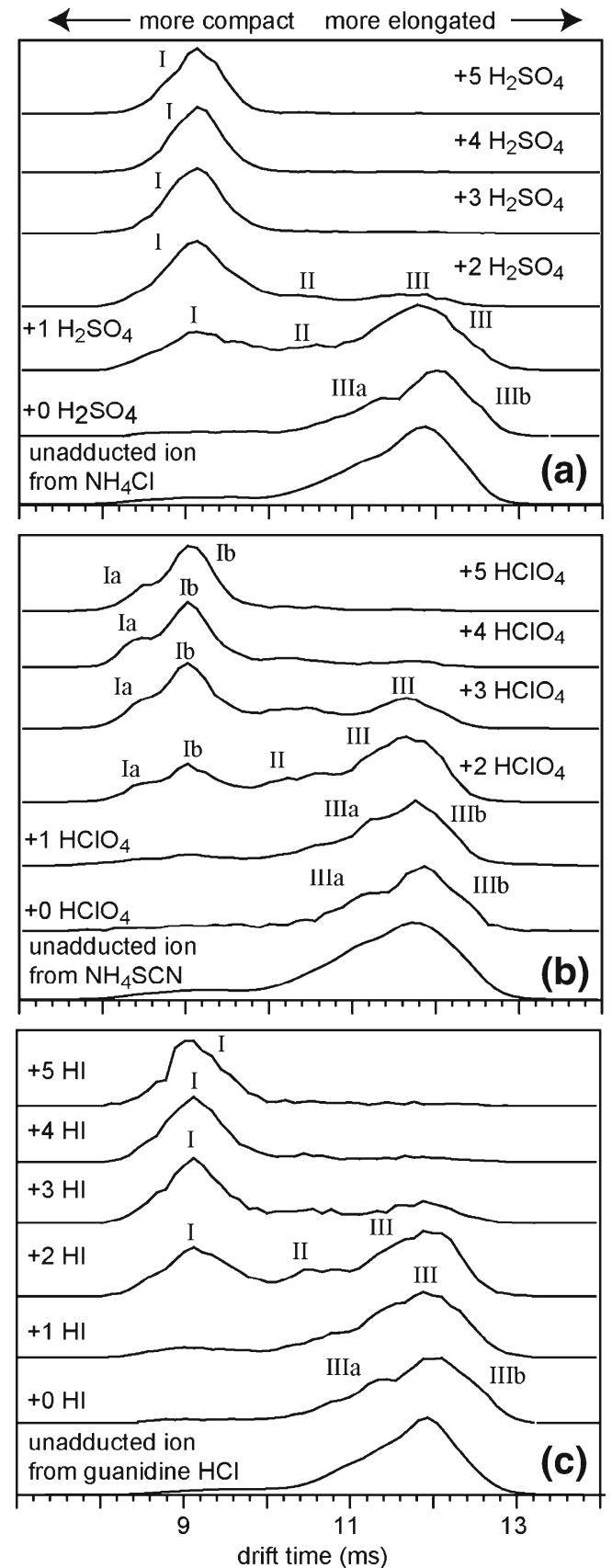

Figure 3. TWIMS drift time distributions of $6+$ ions of ubiquitin formed from aqueous solutions of $5 \mathrm{mM}\left(\mathrm{NH}_{4}\right)_{2} \mathrm{SO}_{4}$ (a), $\mathrm{NH}_{4} \mathrm{ClO}_{4}$ (b), or $\mathrm{NH}_{4} \mathrm{I}$ (c). Distributions are shown for ions with no adducts (bottommost plots) through five adducts (uppermost), and were obtained by integrating intensities across $\mathrm{m} / \mathrm{z}$ values corresponding to each addition from the two-dimensional dataset. The bottom-most plots are unadducted $6+$ ions formed from aqueous solutions of $\mathrm{NH}_{4} \mathrm{Cl}(\mathbf{a})$, $\mathrm{NH}_{4} \mathrm{SCN}$ (b), and guanidinium chloride (c)

same solution as the protein has no measurable effect on the conformation of the unadducted protein ion (Figure 5, bottom plots for each set). Three distinct features are observed, and are labeled III through V.
Adduction of multiple $\mathrm{H}_{2} \mathrm{SO}_{4}$ molecules to cytochrome $c$ $7+$ results in this ion adopting more compact conformations (Figure 5a). With two $\mathrm{H}_{2} \mathrm{SO}_{4}$ molecules adducted, feature III is the dominant peak in the drift profile; the low mobility feature $\mathrm{V}$ is no longer observed, and the abundance of feature IV is lower. A new feature, labeled I is observed in the drift profile for the ion with four $\mathrm{H}_{2} \mathrm{SO}_{4}$ molecules adducted, as well as an unresolved distribution of partiallyfolded conformers (II). Feature III remains the most intense peak in the drift profile for cytochrome $c 7+$ ions with four $\mathrm{H}_{2} \mathrm{SO}_{4}$ molecules adducted. With six $\mathrm{H}_{2} \mathrm{SO}_{4}$ molecules adducted to the protein ion, peak I is much more abundant than feature III, and feature III is not observed with eight $\mathrm{H}_{2} \mathrm{SO}_{4}$ molecules adducted. For these ions, feature $\mathrm{I}$ is the only peak in the drift profile, with some high mobility ions becoming apparent (Ia). These high-mobility ions become more intense with the adduction of ten $\mathrm{H}_{2} \mathrm{SO}_{4}$ molecules to the protein ion, with a relative intensity of $44 \%$ (peak height) of feature I.

Adduction of $\mathrm{HClO}_{4}(5 \mathrm{~b})$ or $\mathrm{HI}(5 \mathrm{c})$ to cytochrome $c$ 7+ also results in the adoption of more compact conformations compared with the unadducted ion. However, the compaction observed for a given number of $\mathrm{HClO}_{4}$ or $\mathrm{HI}$ molecules is not as great as that observed for the same number of $\mathrm{H}_{2} \mathrm{SO}_{4}$ molecules, except at maximal adduction. Feature III is the most intense peak for ions with either two $\mathrm{HClO}_{4}$ or two HI molecules adducted, with feature IV remaining at a relative intensity of $\sim 25 \%$, and no feature $\mathrm{V}$ observed at all. Further reduction of feature IV occurs when four molecules of either $\mathrm{HClO}_{4}$ or $\mathrm{HI}$ are adducted. Adduction of either six $\mathrm{HClO}_{4}$ or six $\mathrm{HI}$ molecules results in formation of the more folded conformers I and II, although feature III is still the dominant peak in both drift profiles. Features I and II become more defined when eight $\mathrm{HClO}_{4}$ or $\mathrm{HI}$ molecules are adducted to the ion, and these drift profiles look very similar to that for cytochrome $c$ 7+ with four $\mathrm{H}_{2} \mathrm{SO}_{4}$ molecules attached, as was the case for ubiquitin. When 10 molecules of either $\mathrm{HClO}_{4}$ or $\mathrm{HI}$ are adducted, feature $\mathrm{I}$ is the most intense peak, and a small amount of feature III remains. The most compact feature, Ia, formed when eight or more $\mathrm{H}_{2} \mathrm{SO}_{4}$ molecules are adducted is not observed with up to $10 \mathrm{HClO}_{4}$ or $10 \mathrm{HI}$ molecules. As observed with ubiquitin, adduction of acid molecules to cytochrome $c$ ions with partially folded conformers results in the protein ions adopting more folded conformations, with sulfate being more efficient at compacting the protein than perchlorate or iodide.

\section{Molecular Adduction to Cytochrome c 6+ and 8+ Ions}

Drift profiles for cytochrome $c 8^{+}$, the highest charge state formed from all three solutions, with varying numbers of molecules of $\mathrm{HClO}_{4}, \mathrm{HI}$, or $\mathrm{H}_{2} \mathrm{SO}_{4}$ adducted are shown to the left of Figure 6. Again, profiles for the unadducted (cytochrome $c+8 \mathrm{H})^{8+}$ formed from the three different 


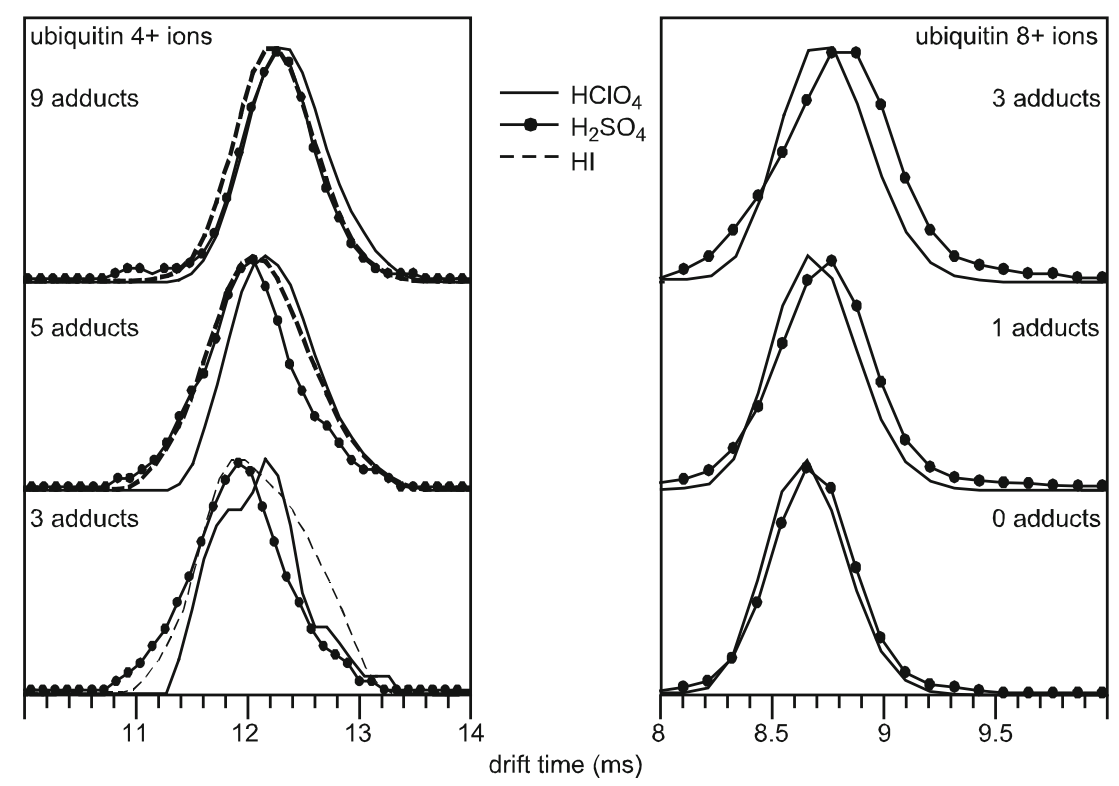

Figure 4. TWIMS drift time distributions for ubiquitin 4+ (left) and 8+ (right) ions formed from aqueous solutions of $5 \mathrm{mM}$ $\mathrm{NH}_{4} \mathrm{ClO}_{4}$ (solid), $\mathrm{NH}_{4} \mathrm{l}$ (dotted), or $\left(\mathrm{NH}_{4}\right)_{2} \mathrm{SO}_{4}$ (filled circles), in increasing order of adduction from top to bottom

solutions are similar to the profile for this ion formed out of water alone (Figure 1b). The drift profile for the (cytochrome $c+8 \mathrm{H})^{8+}$ has two features; a broad high-mobility feature (I), and a low-mobility peak (II). With one molecule adducted to the ion, feature II decreases in intensity, but to varying extents depending on the adducted molecule. Feature II is absent from the drift profile for cytochrome $c$ $8+$ with one $\mathrm{HClO}_{4}$ adducted, and a slightly higher mobility feature (IIa) is observed. Both features IIa and IIb are observed when one HI molecule is adducted. There are also some changes in feature I upon adduction of one $\mathrm{HClO}_{4}, \mathrm{HI}$, or $\mathrm{H}_{2} \mathrm{SO}_{4}$ molecule to the protein. This peak remains broad with one $\mathrm{H}_{2} \mathrm{SO}_{4}$ molecule adducted, whereas this peak is narrower and shifted to lower drift times with one $\mathrm{HClO}_{4}$ or HI adducted. The distributions for adduction of two molecules to cytochrome $c 8+$ also show differences in the features labeled I. There are two high-mobility features in the $\mathrm{H}_{2} \mathrm{SO}_{4}$ drift profile, with feature $\mathrm{Ib}$ being more intense. The relative intensities of these peaks are reversed when two HI molecules are adducted, and feature $\mathrm{Ib}$ is the least pronounced for $\mathrm{HClO}_{4}$. Feature II is not observed when two $\mathrm{HClO}_{4}$ molecules are adducted to the ion, whereas Features $\mathrm{IIa}\left(\mathrm{HI}\right.$ and $\mathrm{H}_{2} \mathrm{SO}_{4}$ ) and $\mathrm{IIb}$ (only $\mathrm{HI}$ ) are still present when two molecules are adducted, but at lower relative abundances compared with those for adduction of a single molecule. The data for cytochrome $c 8+$ is different than those for cytochrome $c 7+$ and the charge states of ubiquitin. Adduction of multiple $\mathrm{H}_{2} \mathrm{SO}_{4}$ molecules to this charge state does not result in the most compaction, whereas multiple adducts of $\mathrm{HClO}_{4}$ does. One possibility could be that features $\mathrm{Ib}$ and $\mathrm{IIa}$ are the products of native-like conformations in solution, whereas feature Ia results from the transfer of a highly folded molten-globule state to the gas phase.
Drift profiles for the cytochrome $c 6^{+}$, the lowest charge state formed from all three solutions, with multiple adductions of $\mathrm{HClO}_{4}, \mathrm{HI}$, and $\mathrm{H}_{2} \mathrm{SO}_{4}$ molecules are shown on the right side of Figure 6 . No unadducted (cytochrome $c+6 \mathrm{H})^{6+}$ is observed. The drift profile for this ion formed from pure water has a single peak, labeled II. A new conformer family is observed upon adduction of two acid molecules (I), and the relative intensities of this new feature depend on the identity of the adducted molecule. Feature I is most intense for $\mathrm{H}_{2} \mathrm{SO}_{4}$ compared with both $\mathrm{HClO}_{4}$ and $\mathrm{HI}$. Feature I is more abundant when five $\mathrm{H}_{2} \mathrm{SO}_{4}$ molecules are adducted, whereas feature II is more abundant when either five $\mathrm{HClO}_{4}$ or HI molecules are adducted. Drift distributions for cytochrome $c 6+$ with ten molecules adducted are similar, with very little of feature II remaining for either $\mathrm{HClO}_{4}$ and $\mathrm{HI}$, and none for $\mathrm{H}_{2} \mathrm{SO}_{4}$. With 15 molecules adducted to the protein, the maximum observed for this charge state, the drift profiles are indistinguishable from one another, and indicate only a single compact structure or family of structures with indistinguishable cross sections. The data for cytochrome $c$ ions, with the exception of the $8+$, suggest that the compaction observed upon maximal adduction of molecules to the protein does not depend on the molecule, and that adduction might occur through salt-bridges that compact the protein to a family of conformations beyond which further compaction is not possible. However, the intensities of intermediate conformations do depend on which molecule is adducted, suggesting different interactions between the molecule and the protein as the molecule is varied. Specifically, the compaction observed for a given number of $\mathrm{H}_{2} \mathrm{SO}_{4}$ molecules adducted is only observed upon the binding of twice as many $\mathrm{HClO}_{4}$ or $\mathrm{HI}$ molecules, further supporting salt-bridge interactions as the method of interaction between the protein and the acid molecules. 

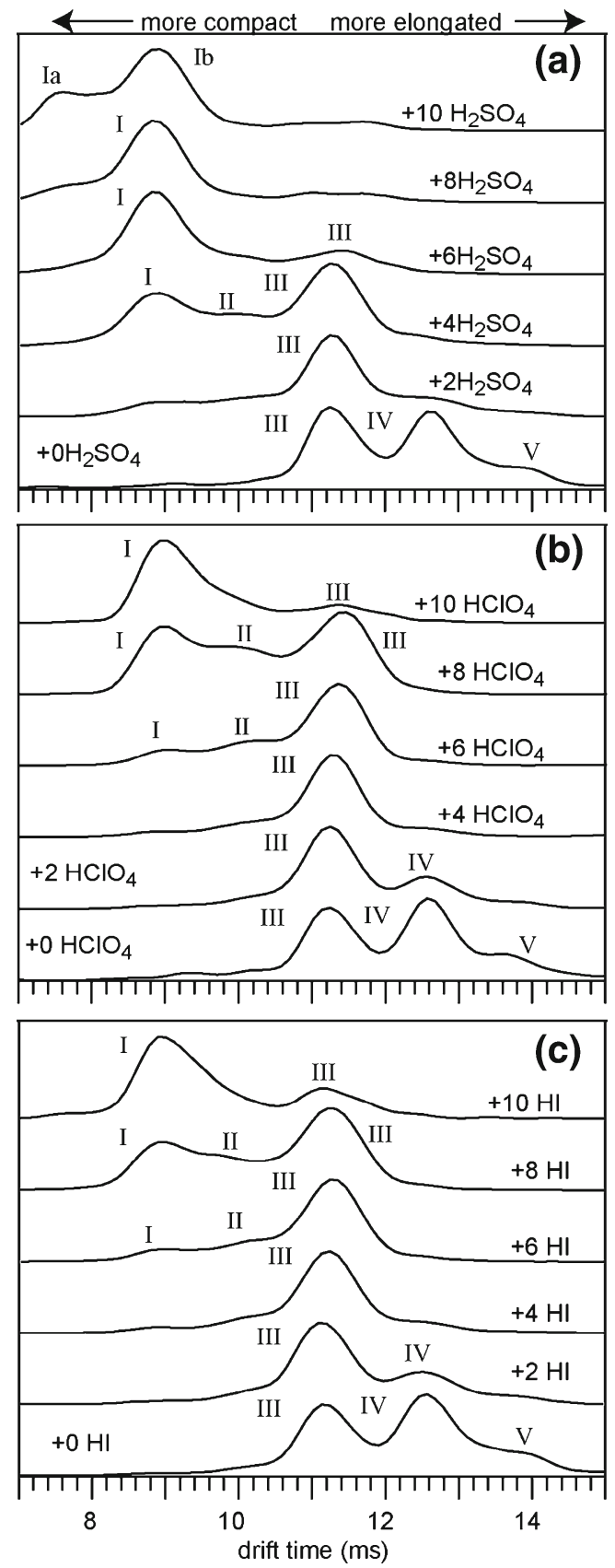

Figure 5. TWIMS drift time distributions for cytochrome $c 7+$ ions formed from aqueous solutions of $5 \mathrm{mM}\left(\mathrm{NH}_{4}\right)_{2} \mathrm{SO}_{4}$ (a), $\mathrm{NH}_{4} \mathrm{ClO}_{4}$ (b), or $\mathrm{NH}_{4} \mathrm{l}$ (c). Distributions are shown for ions with no adducts (bottommost) through 10 adducts (uppermost), and were obtained by integrating intensities across $\mathrm{m} / \mathrm{z}$ values corresponding to each addition from the two-dimensional dataset

\section{Lysozyme and $\alpha$-Lactalbumin with Multiple Adducts of $\mathrm{H}_{2} \mathrm{SO}_{4}, \mathrm{HClO}_{4}$, or $\mathrm{HI}$}

Drift profiles for lysozyme $(\mathrm{pI}=9.32) 7+$ through $9+$ ions, with varying levels of $\mathrm{HClO}_{4}, \mathrm{HI}$, and $\mathrm{H}_{2} \mathrm{SO}_{4}$ adduction are shown in Figure $7 \mathrm{a}-\mathrm{c}$. The mass spectral data (not shown) confirm the disulfide bonds are intact for all solutions, and

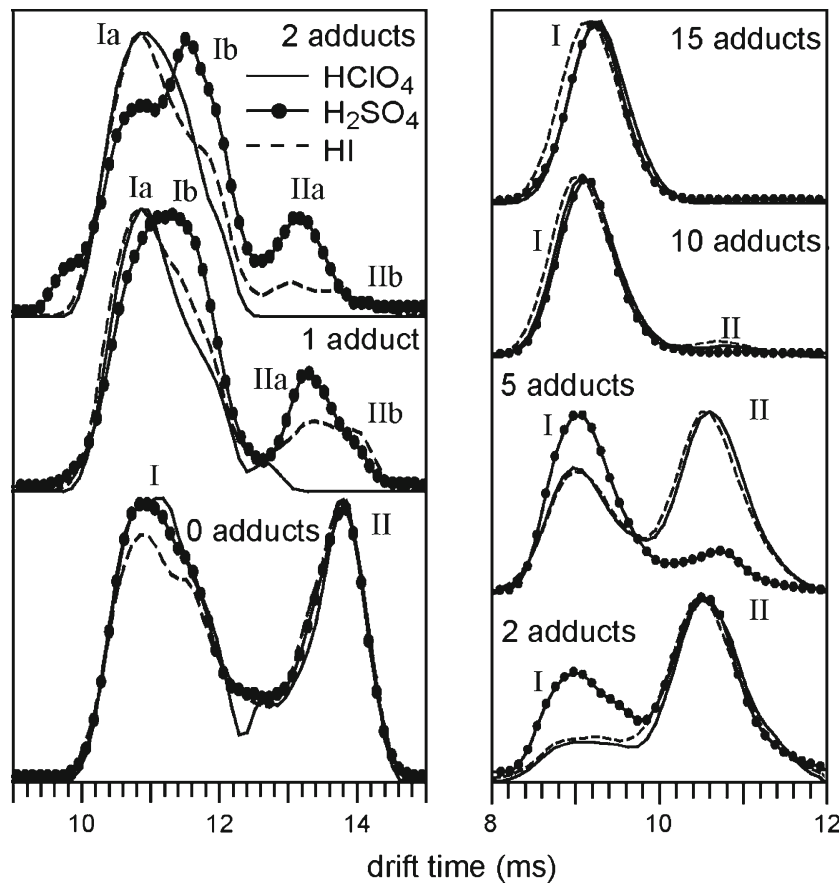

Figure 6. TWIMS drift time distributions for cytochrome $c$ 8+ (left) and 6+ (right) ions formed from aqueous solutions of $5 \mathrm{mM} \mathrm{NH}_{4} \mathrm{ClO}_{4}$ (solid), $\mathrm{NH}_{4}$ l (dotted), or $\left(\mathrm{NH}_{4}\right)_{2} \mathrm{SO}_{4}$ (filled circles), in increasing order of adduction from top to bottom

remain intact throughout the adduction of multiple molecules to the protein ions. For the unadducted $8+$ and $9+$ ions, a single conformer or unresolved family of conformers is observed. As was the case for both ubiquitin and cytochrome $c$, these distributions are indistinguishable from those observed for the bare ions out of water alone (Figure 1c). Although the unadducted $7+$ is not formed from all three solutions, the profile for this ion with the addition of three molecules also has a single peak and is similar to that observed for the unadducted ion formed from pure water (Figure 1c).

Lysozyme was amongst the first proteins for which a reverse Hofmeister series was observed, i.e., chaotropes preserve native conformations whereas kosmotropes improve protein solubility $[11,13]$. Valentine and Clemmer observed modest changes in the conformations of charge states of disulfide-intact lysozyme as the injection energy was varied [60]; comparison of their distributions to those in Figure 1c suggest the protein is somewhat activated in the TWIMS experiments. Despite the four disulfide bonds, this protein can undergo a significant amount of unfolding in the gas phase [60, 82, 83]. However, in these experiments, adduction of multiple acid molecules results in no significant change to the drift profiles of these ions.

$\alpha$-Lactalbumin is an acidic protein $(\mathrm{pI}=4.80)$, which also has four disulfide bonds and a bound calcium ion. Results for the $6+, 7+$, and 9+ charge states are shown in Figure $7 \mathrm{~d}_{-}^{-}$ f. The $6+$ ion was formed from all three solutions, and does not change significantly upon adduction of up to four $\mathrm{HClO}_{4}, \mathrm{HI}$, or $\mathrm{H}_{2} \mathrm{SO}_{4}$ molecules (7d). Results for the $9+$ 

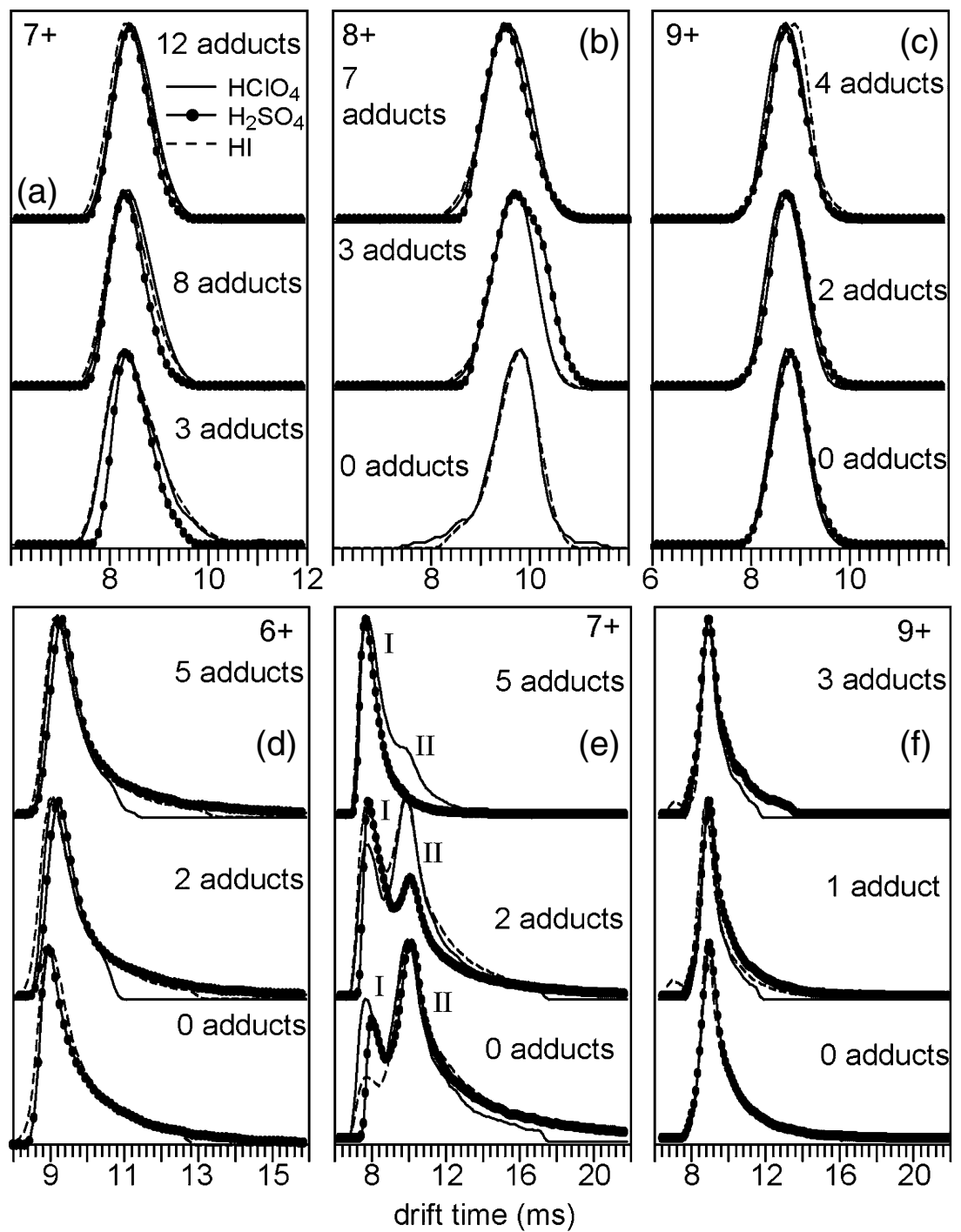

Figure 7. TWIMS drift time distributions for lysozyme 7+ (a), $8+$ (b), and $9+$ (c) ions, as well as $\alpha$-lactalbumin $6+$ (d), $7+$ (e), and 9+ (f) ions formed from aqueous solutions of $5 \mathrm{mM} \mathrm{NH}_{4} \mathrm{ClO}_{4}$ (solid), $\mathrm{NH}_{4} \mathrm{l}$ (dotted), or $\left(\mathrm{NH}_{4}\right)_{2} \mathrm{SO}_{4}$ (filled circles), in increasing order of adduction from top to bottom

ion, which adducted a maximum of three $\mathrm{HClO}_{4}, \mathrm{HI}$, or $\mathrm{H}_{2} \mathrm{SO}_{4}$ molecules, were similar (7f). Adduction of acid molecules to the $7+(7 \mathrm{e})$ results in conformational changes similar to those observed for charge states of ubiquitin and cytochrome $c$. The distributions of conformations for the bare ions formed out of all three solutions differ slightly from one another. There are two features, with feature I less intense for ions formed out of the $5 \mathrm{mM} \mathrm{NH}_{4} \mathrm{I}$ solution. Feature I increases with adduction of two acid molecules, with the largest increase occurring for $\mathrm{H}_{2} \mathrm{SO}_{4}$. With five acid molecules adducted to the 7+, only feature I is observed for $\mathrm{H}_{2} \mathrm{SO}_{4}$ and $\mathrm{HI}$, and a small low-mobility shoulder for $\mathrm{HClO}_{4}$.

With the exception of the salt concentration in the bulk solution, these experiments were designed such that a reverse Hofmeister series would be observed for lysozyme and cytochrome $c$, whereas a direct series would be observed for ubiquitin and $\alpha$-lactalbumin. Adduction of acid molecules to $\alpha$-lactalbumin, ubiquitin, and cytochrome $c$ results in the adoption of more compact structures, and no effect was observed for lysozyme. These proteins span a range of pI from 4.80 to 9.59 , indicating that the compaction of the protein in the gas phase as a result of adduction does not depend strongly on the $\mathrm{pI}$ of the protein in solution. Compaction of conformations would not be anticipated for the attachment of $\mathrm{HClO}_{4}$ or $\mathrm{HI}$ to ubiquitin and $\alpha$-lactalbumin, considering the anions of both acids disrupt the native conformations of these proteins in solution at the $\mathrm{pH}$ used in these studies. Similarly, compaction would not be anticipated for the adduction of $\mathrm{H}_{2} \mathrm{SO}_{4}$ to charge states of cytochrome $c$. Thus, these results for gas-phase ions do not correlate with the Hofmeister effect in solution. A similar conclusion was recently reported for gaseous anion-protein complexes [56]. It is more likely that ion-ion interactions are 
compacting the protein ions, and that the observed changes in conformation do not necessarily reflect any solution-phase characteristics of the ions or the protein.

\section{Discussion and Concluding Remarks}

The Hofmeister series is a widely accepted, albeit not fully understood, cornerstone of structural biology. Whereas molar levels of the salts studied here have varying effects on protein conformation in solution, our experiments show that addition of millimolar levels of $\left(\mathrm{NH}_{4}\right)_{2} \mathrm{SO}_{4}, \mathrm{NH}_{4} \mathrm{ClO}_{4}, \mathrm{NH}_{4} \mathrm{I}, \mathrm{NH}_{4} \mathrm{Cl}$, $\mathrm{NH}_{4} \mathrm{SCN}$, or guanidinium chloride to the ESI solution have no measurable effect on the gas-phase conformations of charge states of ubiquitin, cytochrome $c$, lysozyme, and $\alpha$-lactalbumin compared with the same charge states formed from pure aqueous solutions. Structural changes to proteins in solution are known to occur when the salts are at a concentration of several molar. Although the salt concentration in our experiments are initially three orders of magnitude lower, the anion concentration in the evaporating ESI droplet increases and the final anion molarity the protein is exposed to is unknown. Our data for unadducted protein ions formed out of solutions containing Hofmeister salts suggest that the presence of the salt in the same solution as the protein is insufficient to induce a significant conformational change in the protein, at the concentration and timescale necessary for gas-phase ion formation.

For a given number of adducted molecules, the relative intensity of compact conformers is almost always greater for $\mathrm{H}_{2} \mathrm{SO}_{4}$ than for either $\mathrm{HClO}_{4}$ or $\mathrm{HI}$. Although $\mathrm{SO}_{4}{ }^{2-}$ stabilizes the native conformations of ubiquitin and $\alpha$-lactalbumin at $\mathrm{pH} \sim 7$, observation of more compact conformations upon adduction of $\mathrm{HClO}_{4}$ or $\mathrm{HI}$, both of which are expected to disrupt native elements of secondary structure, does not correlate with the expected Hofmeister effects. Similarly, compaction of cytochrome $c$ upon adduction of multiple $\mathrm{H}_{2} \mathrm{SO}_{4}$ molecules is contrary to the effects of $\mathrm{SO}_{4}{ }^{2-}$ on this protein in solution at $\mathrm{pH} \sim 7$. With a few exceptions, the distributions observed for a given charge state with the maximum number of adducted molecules are similar for all three molecules, suggesting that similar compact conformations are formed. Anion adduction will reduce the effects of Coulomb repulsion through favorable salt-bridging, making it possible for the ion to adopt more folded conformations. Because sulfate is a dianion, it should be more efficient at stabilizing protein conformation through ionic interactions than either perchlorate or iodide, both of which are singly charged. More detailed insights into protein conformational effects induced by anion attachment, including effects of hydrogen bonding and charge, could be obtained by investigating additional anions.

\section{Acknowledgments}

The authors acknowledge financial support from the National Science Foundation (grant CHE-1012833) and
National Institutes of Health (grant 5F32GM093593-02 for fellowship support for S.I.M.). The authors also thank Waters Corporation and Dr. Haichuan Liu and Professor Ewa Witkowska of the UCSF Sandler-Moore Mass Spectrometry Core Facility for the use of their Synapt G2 instruments.

\section{References}

1. Hofmeister, F. Zur Lehre Von Der Wirkung Der Salze. NaunynSchmiedeberg's Arch. Pharmacol. 25, 1-30 (1888)

2. Collins, K.D.: Sticky Ions in Biological Systems. Proc. Natl. Acad. Sci. U.S.A. 92, 5553-5557 (1995)

3. Collins, K.D.: Charge Density-Dependent Strength of Hydration and Biological Structure. Biophys. J. 72, 65-76 (1997)

4. Cacace, M.G., Landau, E.M., Ramsden, J.J.: The Hofmeister Series: Salt and Solvent Effects on Interfacial Phenomena. Q. Rev. Biophys. 30, 241-277 (1997)

5. Kunz, W.: Specific Ion Effects in Liquids, in Biological Systems, and at Interfaces. Pure Appl. Chem. 78, 1611-1617 (2006)

6. Jungwirth, P., Winter, B.: Ions at Aqueous Interfaces: From Water Surface to Hydrated Proteins. Annu. Rev. Phys. Chem. 59, 343-366 (2008)

7. Kunz, W.: Specific Ion Effects in Colloidal and Biological Systems. Curr. Opin. Colloid Interface Sci. 15, 34-39 (2010)

8. Paschek, D., Ludwig, R.: Specific Ion Effects on Water Structure and Dynamics Beyond the First Hydration Shell. Angew. Chem. Int. Edit. 50, 352-353 (2011)

9. Dill, K.A., Truskett, T.M., Vlachy, V., Hribar-Lee, B.: Modeling Water, the Hydrophobic Effect, and Ion Solvation. Annu. Rev. Biophys. Biomolec. Struct. 34, 173-199 (2005)

10. Petersen, P.B., Saykally, R.J.: On the Nature of Ions at the Liquid Water Surface. Annu. Rev. Phys. Chem. 57, 333-364 (2006)

11. Alderton, G., Fevold, H.L.: Direct Crystallization of Lysozyme from Egg White and Some Crystalline Salts of Lysozyme. J. Biol. Chem. 164, 1-5 (1946)

12. Tanford, C., Wagner, M.L.: Hydrogen Ion Equilibria of Lysozyme. $J$. Am. Chem. Soc. 76, 3331-3336 (1954)

13. Rieskautt, M.M., Ducruix, A.F.: Relative Effectiveness of Various Ions on the Solubility and Crystal-Growth of Lysozyme. J. Biol. Chem. 264, 745-748 (1989)

14. Rieskautt, M.M., Ducruix, A.F.: Crystallization of Basic-Proteins by Ion-Pairing. J. Cryst. Growth 110, 20-25 (1991)

15. Bostrom, M., Tavares, F.W., Finet, S., Skouri-Panet, F., Tardieu, A., Ninham, B.W.: Why Forces between Proteins Follow Different Hofmeister Series for $\mathrm{pH}$ above and Below pI. Biophys. Chem. 117, 217-224 (2005)

16. Harding, M.M., Williams, D.H., Woolfson, D.N.: Characterization of a Partially Denatured State of a Protein by 2-Dimensional NMR Reduction of the Hydrophobic Interactions in Ubiquitin. Biochemistry 30, 3120-3128 (1991)

17. Jeng, M.F., Englander, S.W., Elove, G.A., Wand, A.J., Roder, H.: Structural Description of Acid-Denatured Cytochrome c by HydrogenExchange and 2D NMR. Biochemistry 29, 10433-10437 (1990)

18. Hamada, D., Kidokoro, S.I., Fukada, H., Takahashi, K., Goto, Y.: SaltInduced Formation of the Molten Globule State of Cytochrome c Studied by Isothermal Titration Calorimetry. Proc. Natl. Acad. Sci. U.S. A. 91, 10325-10329 (1994)

19. Freire, M.G., Neves, C.M.S.S., Silva, A.M.S., Santos, L.M.N.B.F., Marrucho, I.M., Rebelo, L.P.N., Shah, J.K., Maginn, E.J., Coutinho, J. A.P.: ${ }^{1} \mathrm{H}$ NMR and Molecular Dynamics Evidence for an Unexpected Interaction on the Origin of Salting-in/Salting-out Phenomena. J. Phys. Chem. B 114, 2004-2014 (2010)

20. Holz, M., Grunder, R., Sacco, A., Meleleo, A.: Nuclear-MagneticResonance Study of Self-Association of Small Hydrophobic Solutes in Water-Salt Effects and the Lyotropic Series. J. Chem. Soc.-Faraday Trans. 89, 1215-1222 (1993)

21. McNay, J.L.M., O'Connell, J.P., Fernandez, E.J.: Protein Unfolding During Reversed-Phase Chromatography: II. Role of Salt Type and Ionic Strength. Biotechnol. Bioeng. 76, 233-240 (2001)

22. Rydall, J.R., Macdonald, P.M.: Investigation of Anion Binding to Neutral Lipid-Membranes Using H-2 NMR. Biochemistry 31, 10921099 (1992) 
23. Uejio, J.S., Schwartz, C.P., Duffin, A.M., Drisdell, W.S., Cohen, R.C., Saykally, R.J.: Characterization of Selective Binding of Alkali Cations with Carboxylate by X-Ray Absorption Spectroscopy of Liquid Microjets. Proc. Natl. Acad. Sci. U.S.A. 105, 6809-6812 (2008)

24. Schwartz, C.P., Uejio, J.S., Duffin, A.M., England, A.H., Kelly, D.N., Prendergast, D., Saykally, R.J.: Investigation of Protein Conformation and Interactions with Salts Via X-Ray Absorption Spectroscopy. Proc. Natl. Acad. Sci. U S. A. 107, 14008-14013 (2010)

25. Omta, A.W., Kropman, M.F., Woutersen, S., Bakker, H.J.: Negligible Effect of Ions on the Hydrogen-Bond Structure in Liquid Water. Science 301, 347-349 (2003)

26. Chen, X., Yang, T., Kataoka, S., Cremer, P.S.: Specific Ion Effects on Interfacial Water Structure near Macromolecules. J. Am. Chem. Soc. 129, 12272-12279 (2007)

27. Washabaugh, M.W., Collins, K.D.: The Systematic Characterization by Aqueous Column Chromatography of Solutes Which Affect Protein Stability. J. Biol. Chem. 261, 2477-2485 (1986)

28. Kiriukhin, M.Y., Collins, K.D.: Dynamic Hydration Numbers for Biologically Important Ions. Biophys. Chem. 99, 155-168 (2002)

29. Jenkins, H.D.B., Marcus, Y.: Viscosity B-Coefficients of Ions in Solution. Chem. Rev. 95, 2695-2724 (1995)

30. Enderby, J.E.: Ion Solvation Via Neutron-Scattering. Chem. Soc. Rev. 24, 159-168 (1995)

31. Mason, P.E., Neilson, G.W., Dempsey, C.E., Barnes, A.C., Cruickshank, J.M.: The Hydration Structure of Guanidinium and Thiocyanate Ions: Implications for Protein Stability in Aqueous Solution. Proc. Natl. Acad. Sci. U. S. A. 100, 4557-4561 (2003)

32. Sanderson, P.W., Lis, L.J., Quinn, P.J., Williams, W.P.: The Hofmeister Effect in Relation to Membrane Lipid Phase-Stability. Biochimica Et Biophysica Acta 1067, 43-50 (1991)

33. Hribar, B., Southall, N.T., Vlachy, V., Dill, K.A.: How Ions Affect the Structure of Water. J. Am. Chem. Soc. 124, 12302-12311 (2002)

34. Pegram, L.M., Record, M.T.: Hofmeister Salt Effects on Surface Tension Arise from Partitioning of Anions and Cations between Bulk Water and the Air-Water Interface. J. Phys. Chem. B. 111, 5411-5417 (2007)

35. Smith, J.D., Saykally, R.J., Geissler, P.L.: The Effects of Dissolved Halide Anions on Hydrogen Bonding in Liquid Water. J. Am. Chem. Soc. 129, 13847-13856 (2007)

36. O'Brien, J.T., Prell, J.S., Bush, M.F., Williams, E.R.: Sulfate Ion Patterns Water at Long Distance. J. Am. Chem. Soc. 132, 8248-8249 (2010)

37. Prell, J.S., O'Brien, J.T., Williams, E.R.: Structural and Electric Field Effects of Ions in Aqueous Nanodrops. J. Am. Chem. Soc. 133, 4810$4818(2011)$

38. Huber, C.G., Buchmeiser, M.R.: On-Line Cation Exchange for Suppression of Adduct Formation in Negative-Ion Electrospray Mass Spectrometry of Nucleic Acids. Anal. Chem. 70, 5288-5295 (1998)

39. Iavarone, A.T., Udekwu, O.A., Williams, E.R.: Buffer Loading for Counteracting Metal Salt-Induced Signal Suppression in Electrospray Ionization. Anal. Chem. 76, 3944-3950 (2004)

40. Chowdhury, S.K., Katta, V., Beavis, R.C., Chait, B.T.: Origin and Removal of Adducts (Molecular Mass=98-U) Attached to Peptide and Protein Ions in Electrospray Ionization Mass-Spectra. J. Am. Soc. Mass Spectrom. 1, 382-388 (1990)

41. Pan, J.X., Xu, K., Yang, X.D., Choy, W.Y., Konermann, L.: SolutionPhase Chelators for Suppressing Nonspecific Protein-Metal Interactions in Electrospray Mass Spectrometry. Anal. Chem. 81, 5008-5015 (2009)

42. Kellersberger, K.A., Yu, E.T., Merenbloom, S.I., Fabris, D.: Atmospheric Pressure MALDI-FTMS of Normal and Chemically Modified RNA. J. Am. Soc. Mass Spectrom. 16, 199-207 (2005)

43. Kharlamova, A., Prentice, B.M., Huang, T.Y., McLuckey, S.A.: Electrospray Droplet Exposure to Gaseous Acids for Reduction of Metal Counter-Ions in Nucleic Acid Ions. Int. J. Mass Spectrom. 300, 158-166 (2010)

44. Constantopoulos, T.L., Jackson, G.S., Enke, C.G.: Effects of Salt Concentration on Analyte Response Using Electrospray Ionization Mass Spectrometry. J. Am. Soc. Mass Spectrom. 10, 625-634 (1999)

45. Pan, P., McLuckey, S.A.: The Effect of Small Cations on the Positive Electrospray Responses of Proteins at Low pH. Anal. Chem. 75, 5468 5474 (2003)

46. Mirza, U.A., Chait, B.T.: Effects of Anions on the Positive-Ion Electrospray-Ionization Mass-Spectra of Peptides and Proteins. Anal. Chem. 66, 2898-2904 (1994)
47. Prakash, H., Kansara, B.T., Mazumdar, S.: Effects of Salts on the Charge-State Distribution and the Structural Basis of the Most-Intense Charge-State of the Gaseous Protein Ions Produced by Electrospray Ionization. Int. J. Mass Spectrom. 289, 84-91 (2010)

48. Stephenson, J.L., McLuckey, S.A.: Counting Basic Sites in Oligopeptides Via Gas-Phase Ion Chemistry. Anal. Chem. 69, 281-285 (1997)

49. Kruger, R., Karas, M.: Formation and Fate of Ion Pairs During MALDI Analysis: Anion Adduct Generation as an Indicative Tool to Determine Ionization Processes. J. Am. Soc. Mass Spectrom. 13, 1218-1226 (2002)

50. Flick, T.G., Merenbloom, S.I., Williams, E.R.: A Simple and Robust Method for Determining the Number of Basic Sites in Peptides and Proteins Using Electrospray Ionization Mass Spectrometry. Anal. Chem. 83, 2210-2214 (2011)

51. Loo, J.A.: Electrospray Ionization Mass Spectrometry: A Technology for Studying Noncovalent Macromolecular Complexes. Int. J. Mass Spectrom. 200, 175-186 (2000)

52. Heck, A.J.R., van den Heuvel, R.H.H.: Investigation of Intact Protein Complexes by Mass Spectrometry. Mass Spectrom. Rev. 23, 368-389 (2004)

53. Sterling, H.J., Batchelor, J.D., Wemmer, D.E., Williams, E.R.: Effects of Buffer Loading for Electrospray Ionization Mass Spectrometry of a Noncovalent Protein Complex That Requires High Concentrations of Essential Salts. J. Am. Soc. Mass Spectrom. 21, 1045-1049 (2010)

54. Ruotolo, B.T., Benesch, J.L.P., Sandercock, A.M., Hyung, S.J., Robinson, C.V.: Ion Mobility-Mass Spectrometry Analysis of Large Protein Complexes. Nat. Protoc. 3, 1139-1152 (2008)

55. Freeke, J., Robinson, C.V., Ruotolo, B.T.: Residual Counter Ions Can Stabilize a Large Protein Complex in the Gas Phase. Int. J. Mass Spectrom. 298, 91-98 (2010)

56. Han, L., Hyung, S.-J., Mayers, J.J.S., Ruotolo, B.T.: Bound Anions Differentially Stabilize Multiprotein Complexes in the Absence of Bulk Solvent. J. Am. Chem. Soc. 133, 11358-11367 (2011)

57. Flick, T. G.; Merenbloom, S. I.; Williams, E. R. Anion Effects on Sodium Ion and Acid Molecule Adduction to Protein Ions in Electrospray Ionization Mass Spectrometry. J. Am. Soc. Mass Spectrom. (2011). doi:10.1007/s13361-011-0218-5.

58. Pringle, S.D., Giles, K., Wildgoose, J.L., Williams, J.P., Slade, S.E., Thalassinos, K., Bateman, R.H., Bowers, M.T., Scrivens, J.H.: An Investigation of the Mobility Separation of Some Peptide and Protein Ions Using a New Hybrid Quadrupole/Traveling Wave IMS/OA-TOF Instrument. Int. J. Mass Spectrom. 261, 1-12 (2007)

59. Clemmer, D.E., Hudgins, R.R., Jarrold, M.F.: Naked Protein Conformations: Cytochrome c in the Gas Phase. J. Am. Chem. Soc. 117, 10141-10142 (1995)

60. Valentine, S.J., Anderson, J.G., Ellington, A.D., Clemmer, D.E.: Disulfide-Intact and -Reduced Lysozyme in the Gas Phase: Conformations and Pathways of Folding and Unfolding. J. Phys. Chem. B 101, 3891-3900 (1997)

61. Shelimov, K.B., Clemmer, D.E., Hudgins, R.R., Jarrold, M.F.: Protein Structure in Vacuo: Gas-Phase Confirmations of BPTI and Cytochrome c. J. Am. Chem. Soc. 119, 2240-2248 (1997)

62. Badman, E.R., Hoaglund-Hyzer, C.S., Clemmer, D.E.: Monitoring Structural Changes of Proteins in an Ion Trap over 10-200 ms: Unfolding Transitions in Cytochrome c Ions. Anal. Chem. 73, 60006007 (2001)

63. Myung, S., Badman, E.R., Lee, Y.J., Clemmer, D.E.: Structural Transitions of Electrosprayed Ubiquitin Ions Stored in an Ion Trap over $10 \mathrm{~ms}$ to 30 s. J. Phys. Chem. A 106, 9976-9982 (2002)

64. Suckau, D., Shi, Y., Beu, S.C., Senko, M.W., Quinn, J.P., Wampler, F. M., McLafferty, F.W.: Coexisting Stable Conformations of Gaseous Protein Ions. Proc. Natl. Acad. Sci. U.S.A. 90, 790-793 (1993)

65. Wood, T.D., Chorush, R.A., Wampler, F.M., Little, D.P., O'Connor, P. B., McLafferty, F.W.: Gas-Phase Folding and Unfolding of Cytochrome c Cations. Proc. Natl. Acad. Sci. U.S.A. 92, 2451-2454 (1995)

66. Freitas, M.A., Hendrickson, C.L., Emmett, M.R., Marshall, A.G.: GasPhase Bovine Ubiquitin Cation Conformations Resolved by Gas-Phase Hydrogen/Deuterium Exchange Rate and Extent. Int. J. Mass Spectrom. $\mathbf{1 8 5 / 1 8 6 / 1 8 7}, 565-575$ (1999)

67. Li, J.W., Taraszka, J.A., Counterman, A.E., Clemmer, D.E.: Influence of Solvent Composition and Capillary Temperature on the Conformations of Electrosprayed Ions: Unfolding of Compact Ubiquitin Conformers from Pseudonative and Denatured Solutions. Int. J. Mass Spectrom. 187, 37-47 (1999) 
68. Gatlin, C.L., Turecek, F.: Acidity Determination in Droplets Formed by Electrospraying Methanol-Water Solutions. Anal. Chem. 66, 712-718 (1994)

69. Ruotolo, B.T., Giles, K., Campuzano, I., Sandercock, A.M., Bateman, R.H., Robinson, C.V.: Evidence for Macromolecular Protein Rings in the Absence of Bulk Water. Science 310, 1658-1661 (2005)

70. Bush, M.F., Hall, Z., Giles, K., Hoyes, J., Robinson, C.V., Ruotolo, B. T.: Collision Cross Sections of Proteins and Their Complexes: A Calibration Framework and Database for Gas-Phase Structural Biology. Anal. Chem. 82, 9557-9565 (2010)

71. Michaelevski, I., Eisenstein, M., Sharon, M.: Gas-Phase Compaction and Unfolding of Protein Structures. Anal. Chem. 82, 9484-9491 (2010)

72. Morsa, D., Gabelica, V., De Pauw, E.: Effective Temperature of Ions in Traveling Wave Ion Mobility Spectrometry. Anal. Chem. 83, 57755782 (2011)

73. Zhong, Y., Hyung, S.J., Ruotolo, B.T.: Characterizing the Resolution and Accuracy of a Second-Generation Traveling-Wave Ion Mobility Separator for Biomolecular Ions. Analyst 136, 3534-3541 (2011)

74. Shvartsburg, A.A., Smith, R.D.: Fundamentals of Traveling Wave Ion Mobility Spectrometry. Anal. Chem. 80, 9689-9699 (2008)

75. Valentine, S.J., Counterman, A.E., Clemmer, D.E.: Conformer-Dependent Proton-Transfer Reactions of Ubiquitin Ions. J. Am. Soc. Mass Spectrom. 8, 954-961 (1997)

76. Koeniger, S.L., Clemmer, D.E.: Resolution and Structural Transitions of Elongated States of Ubiquitin. J. Am. Soc. Mass Spectrom. 18, 322-331 (2007)
77. Srebalus, C.A., Li, J.W., Marshall, W.S, Clemmer, D.E.: Gas Phase Separations of Electrosprayed Peptide Libraries. Anal. Chem. 71, 39183927 (1999)

78. Ruotolo, B.T., Gillig, K.J., Stone, E.G., Russell, D.H., Fuhrer, K., Gonin, M., Schultz, J.A.: Analysis of Protein Mixtures by MatrixAssisted Laser Desorption Ionization-Ion Mobility-Orthogonal-Timeof-Flight Mass Spectrometry. Int. J. Mass Spectrom. 219, 253-267 (2002)

79. McLean, J.A., Russell, D.H.: Sub-Femtomole Peptide Detection in Ion Mobility-Time-of-Flight Mass Spectrometry Measurements. J. Proteome Res. 2, 427-430 (2003)

80. Woods, A.S., Ugarov, M., Egan, T., Koomen, J., Gillig, K.J., Fuhrer, K., Gonin, M., Schultz, J.A.: Lipid/Peptide/Nucleotide Separation with MALDI-Ion Mobility-TOF MS. Anal. Chem. 76, 2187-2195 (2004)

81. Robinson, E.W., Garcia, D.E., Leib, R.D., Williams, E.R.: Enhanced Mixture Analysis of Poly(Ethylene Glycol) Using High-Field Asymmetric Waveform Ion Mobility Spectrometry Combined with Fourier Transform Ion Cyclotron Resonance Mass Spectrometry. Anal. Chem. 78, 2190-2198 (2006)

82. Gross, D.S., Schnier, P.D., Rodriguez-Cruz, S.E., Fagerquist, C.K., Williams, E.R.: Conformations and Folding of Lysozyme Ions in Vacuo. Proc. Natl. Acad. Sci. U.S.A. 93, 3143-3148 (1996)

83. Sterling, H., Prell, J., Cassou, C., Williams, E.: Protein Conformation and Supercharging with DMSO from Aqueous Solution. J. Am. Soc. Mass Spectrom. 22, 1178-1186 (2011) 